anales de psicología / annals of psychology

2019, vol. 35, nº 1 (january), 106-115

http://dx.doi.org/10.6018/analesps.35.1.297711
(C) Copyright 2019: Editum. Servicio de Publicaciones de la Universidad de Murcia. Murcia (Spain) ISSN print edition: 0212-9728. ISSN on line edition (http://revistas.um.es/analesps): 1695-2294.

On line edition License Creative Commons 4.0: BY-NC-ND

\title{
Psychosocial risk factors, organizational conflict and job satisfaction in Health professionals: A SEM model
}

\author{
Elena Sureda ${ }^{1,3}$, Javier Mancho ${ }^{2}$, and Albert Sesé3,* \\ 1 Organizational Development Department, University Hospital Son Espases, Palma, Balearic Islands, (Spain) \\ 2 Prevention Service, Hospital Son Llàtzer, Palma, Balearic Islands, (Spain) \\ 3 Department of Psychology, Balearic Islands University, Palma, Balearic Islands, (Spain)
}

Título: Factores de riesgo psicosocial, conflicto organizacional y satisfacción laboral en profesionales de la Salud: Un modelo de ecuaciones estructurales.

Resumen: Objetivo: Poner a prueba un modelo de interdependencia sobre el efecto que los factores de riesgo psicosocial generan sobre el conflicto organizacional y la satisfacción laboral en profesionales sanitarios. Método: Se utilizó un diseño selectivo transversal con una muestra de 249 trabajadores de un hospital público. Los riesgos psicosociales se evaluaron mediante la herramienta F-PSICO, la variable conflicto organizacional fue operacionalizada mediante un conjunto de indicadores contenidos en una encuesta elaborada por un equipo multidisciplinar de profesionales sanitarios expertos en mediación laboral; y la satisfacción laboral fue medida con cuatro dimensiones del cuestionario Font Roja. El ajuste del modelo se estimó con modelos de ecuaciones estructurales. Resultados: Se obtuvo un ajuste adecuado del modelo, que supone que cuanto mayor es el riesgo psicosocial, mayor es el conflicto organizacional, y menor la satisfacción laboral percibida. También sitúa la conflictividad laboral como mediadora entre los riesgos psicosociales y la satisfacción laboral. Conclusiones: La contribución única del estudio aporta evidencias empíricas del papel de predictor directo de los riesgos psicosociales sobre la conflictividad en el lugar de trabajo para los profesionales de la salud. Así, la prevención del riesgo psicosocial puede ser una vía eficiente para reducir la conflictividad y para aumentar la satisfacción laboral.

Palabras clave: Factores de riesgo psicosocial; Conflicto organizacional; Satisfacción laboral; Modelos de ecuaciones estructurales, Profesionales de la Salud.

\section{Introduction}

Psychosocial risks refer to the occupational risks associated with those aspects of work design and the organization and management of work, and their social and environmental contexts, which have the potential for causing psychological or physical harm (European Agency for Health and Safety at Work, 2007). Psychosocial risks are associated with negative psychological, physical, and social outcomes that arise from both unfavorable organization and management in the workplace, which include but is not limited to excessively demanding work and/or insufficient time to complete tasks, role conflict and role ambiguity, ineffective communication, poorly managed organizational change and job insecurity, and difficulty in combining work commitments with personal life (Toukas, Delichas, Toufekoula, \& Spyrouli, 2015). Work-related psychosocial factors have been shown as major contributors to mental health problems so that mental health

* Correspondence address [Dirección para correspondencia]: Prof. Dr. Albert Sesé. Faculty of Psychology. Balearic Islands University. Ctra. de Valldemossa, km. 7'5. 07122 Palma (Spain).

E-mail: albert.sese@,uib.es

(Article received: 23-06-2017; revised: 14-12-2017; accepted: 24-03-2018)
Abstract: Objective: To test an interdependence model about the effect that psychosocial risk factors generate over organizational conflict and job satisfaction in Health professionals. Method: A cross-sectional design was implemented with a sample of 249 workers of a public hospital. Psychosocial risk was assessed with F-PSICO method; the latent variable organizational conflict was built using a set of indicators that had been developed from a specific survey made by a multidisciplinary team of health professionals with training in labor mediation; and the latent variable job satisfaction was operationalized with four subdimensions of "Font Roja" questionnaire. The fit of the model was estimated with SEM techniques. Results: Results confirm the adequate fit of the model that posits that the greater the psychosocial risk, the greater is the organizational conflict, and lower the perceived job satisfaction. The model also locates the organizational conflict as mediator variable between the risk and job satisfaction. Conclusions: The unique contribution of this study brings empirical evidence about the predictor role of psychosocial risks over both the organizational conflict and job satisfaction at the workplace in Health professionals. Therefore, psychosocial risk prevention can be an efficient way to reduce conflict levels and to increase job satisfaction.

Keywords: Psychosocial risk factors; Organizational conflict; Job satisfaction; Structural Equation Modelling; Health professionals. complaints such as stress, depression or anxiety are the second most frequently reported work-related health problem in European countries after musculoskeletal diseases (Tomaschek, Lütke, Melzer, Debitz, \& Buruck, 2018).

Although the prevalence and impact of psychosocial risks is now widely acknowledged as a priority in Health \& Safety $(\mathrm{H} \& \mathrm{~S})$ in Europe, there is an importance resistance by key stakeholders in prioritizing psychosocial risk management both in business and policy making (Leka, Van Wassenhove, \& Jain, 2015). One reason for this barrier is that psychosocial risks are not easy to link directly to classical understandings of what is a risk to H\&S (Walters, 2011). It is also important to note that psychosocial risks would be managed neither solely through a H\&S perspective nor through solely from a human resource management perspective, but from a strategic perspective both at organizational and at policy level (Langenhan, Leka, \& Jain, 2013).

Despite of these barriers, there is empirical evidence about to reducing the level of psychosocial risk has a positive effect on workers' satisfaction, well-being and health (Aust \& Ducki, 2004; Kompier, Aust, van den Berg, \& Siegrist, 2000; Kristensen, 2000). Supervision and leadership, and associated psychosocial risks (conflict and role ambiguity, development 
opportunities, and social support) can be also considered as powerful predictors of job satisfaction and intention to disengage from the organization (Acker, 2004). The influence that leadership has on psychosocial risk factors and job satisfaction forces managers to consider strategies of change that affect the labor aspects, to increase job satisfaction and achieve a higher level of well-being and organizational commitment. Supervisor's support appears as a moderating variable in the relationship between workload and emotional exhaustion and job satisfaction (Baeriswyl, Krause, \& Schwaninger, 2016). In turn, Cortese, Colombo and Ghislieri (2010) argue that increasing satisfaction means improving support for coordination, work organization, family reconciliation policies and personal counseling programs. It seems reasonable to interpret that the workers not only wish that there can be perceived an interest in their work, but also that there should be some form of recognition.

Another important variable is organizational conflict, and its possible relationship, both with psychosocial risks and with job satisfaction. Although the importance of psychosocial risk in work for employees' health is well documented, the effects of the style of conflict management have generally received less attention (Hyde, Jappinen, Theorell, \& Oxenstierna, 2006). Literature findings indicate that a constructive approach to conflict, through integration and commitment, rather than through domination or obligation, is essential to increase employee satisfaction and productivity, and in turn reduce abandonment (Benitez, Medina, \& Munduate, 2012; Choi, 2013; Lee, 2009; Springs, 2016). The role of supervisors and middle managers to improve satisfaction and innovation through appropriate conflict management is critical (Chen, Zhao, Liu, \& Wu, 2012). Effective conflict management can also improve teamwork, increase productivity, and satisfaction of employees as well as customers (Williams, 2012). Other studies have analyzed the effect of conflict typology (relational or task-centered) and conclude that both have a negative effect on job satisfaction (Guerra, Martínez, Munduate, \& Medina, 2005). The conflicts more related to the task as the inequality in the distribution of workloads are affected by the psychosocial risks of mental load and role definition. However, Todorova, Bear, and Weingart (2014) point out that the task-related conflict can favor information gain, provoking motivation and interest for the task, as long as the expression of the task and its frequency are not intense. Yang (2014) points out that the cooperative resolution of conflicts can be encouraged from a type of leadership that promotes the commitment of change and provides inspiration and motivation, in short, job satisfaction. McDonald, Vickers, Mohan, Wilkes, and Jackson (2010) propose the potential of spaces for dialogue (and support) to improve conflict resolution, satisfaction, resilience and collaboration among professionals. Thus, the literature presents an important consensus that the level of conflict and the style of management of conflicts in the workplace have a substantial influence on job satisfaction, and therefore on individual, group and organizational effectiveness.
The Health sector is especially vulnerable to psychosocial risks and several studies have analyzed its relationship with job satisfaction (Acker, 2004; Hall, Dollard, \& Coward, 2010; López-Montesinos, 2013; Martín, Luceño, Jaén, \& Rubio, 2007; McCaughey, Turner, Kim, Dellifraine, \& McGhan, 2015), or with somatic symptoms, pain, psychological harassment, fatigue, stress, or burnout (Bültmann, Kant, Van der Brandt, \& Kasl, 2002; Coelho, Tavares, Lourenço, \& Lima, 2015; Freimann \& Merisalu, 2015; Saastamoinen, Laaksonen, Leino-Arjas, \& Lahelma, 2009). The mobilization of too many strong emotions and a very complex organizational structure can lead to emotional exhaustion particularly for jobs involving an interaction with the public, such as hospital workers dealing with patients and their families (Roland-Lévy, Lemoine, \& Jeoffrion, 2014).

Organizational conflict has also high-prevalence in Health professional contexts. The review of the literature developed by Kim et al. (2017) concludes that perceptions of a disrespectful working environment and poor collaborative work are the main consequences of interpersonal conflict; at the organizational level the main sources of conflict are the role ambiguity of Health professionals, the inadequate structure of communication channels, and inefficient workflows, negatively affecting job satisfaction of Health professionals and the intention to remain or abandon. Although there is evidence of increased satisfaction in the presence of low levels of conflict, given the real possibility of resolution (Todorova et al., 2014), Health professionals may experience dissatisfaction, due to different causes, which in turn contribute to increase conflict (or vice versa). Kaitelidou et al. (2012) point out that the main causes of conflict in the hospital setting are organizational and their resolution is based on avoidance strategies. In this sense, Tabak and Koprak (2007) affirm that the use of avoidant strategies in conflict management correlates with a higher level of stress. However, other studies conclude that nurses opt for non-avoidant constructive approaches (Lin, 2003; Scher, 2006). Regardless of the most prevalent strategy, what seems to be proven is that the style of conflict resolution adopted affects job satisfaction (Montoro-Rodríguez \& Small, 2006). There is also evidence on the relationship between role conflict and role ambiguity, and job satisfaction (Torressen, 2000), burnout (Olivares-Faúndez, Gil-Monte, Mena, Jélvez-Wilke, \& Figuereido-Ferraz, 2014; Piko, 2006), or resilience (Soler, Fernández \& de Pedro, 2016).

Despite of all this scientific evidence about the bivariate relationships between psychosocial risks, organizational conflict, and job satisfaction, to our knowledge there are no studies that have conjointly analyzed the effects of interaction between these three variables. For this reason, and trying to cover this gap in the literature, it seems reasonable to prove that psychosocial risks can increase organizational conflict levels, and both variables exert a negative effect over job satisfaction. More specifically, some authors demand new evidence on the causes and consequences of conflicts in the 
health sector (Almost, Doran, Hall, \& Laschinger, 2010) to develop preventive and intervention strategies.

The aim of this paper was to test a theoretical model using a Structural Equation Modeling (SEM) approach in order to obtain empirical evidence about the relationships among psychosocial risk factors, organizational conflict and job satisfaction with Health professionals in a hospital setting. A structural model (Figure 1) included the three considered variables as latent variables: both Psychosocial risk and Job satisfaction were represented as reflective latent variables, and Organizational conflict as a formative latent variable. The model posited that psychosocial risk is a direct predictor of both organizational conflict and job satisfaction, with a positive and negative relationship respectively expected. In turn, organizational conflict is likely to be related directly and negatively to job satisfaction. On this way, organizational conflict is hypothesized as a mediator variable between risk and satisfaction. In consequence, the model posited that a higher level of psychosocial risk should increase the level of organizational conflict, and decrease the job satisfaction; and in turn, more organizational conflict should negatively impact over job satisfaction. The main goal of this study was to assess the fit of the hypothesized model and to discuss the obtained empirical evidence in comparison to literature main findings.

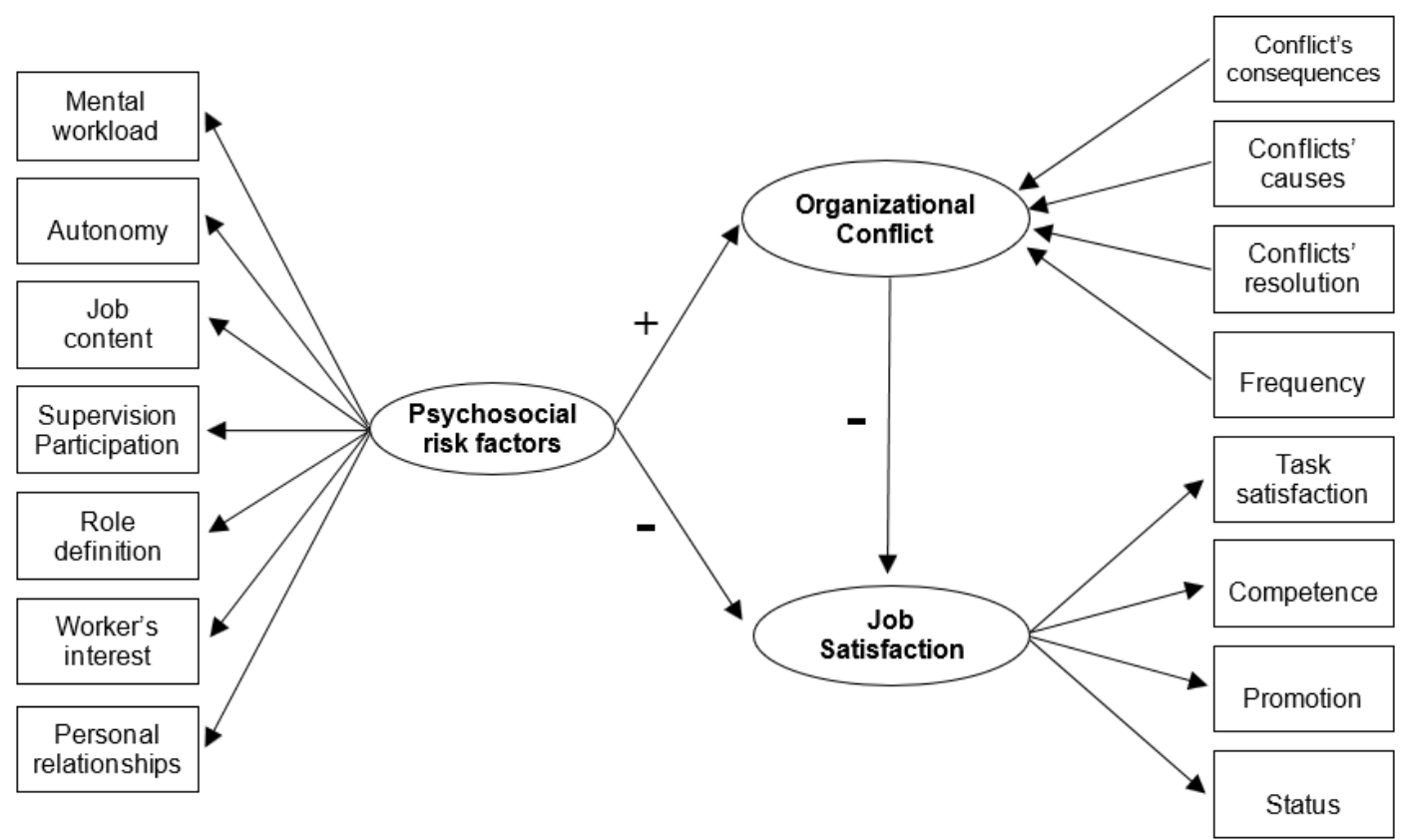

Figure 1. Theoretical model diagram about the expected relationships among the latent variables Psychosocial risk factors, Organizational conflict, and Job satisfaction.

\section{Methods}

\section{Design}

A cross-sectional retrospective ex-post-facto design with a single group was used. An incidental sampling procedure with hospital staff was implemented. Absenteeism and rotation indexes of the hospital services were taken into account for sampling, and statistical representativeness, as well as the number of psychosocial risk reports submitted to the Prevention Service.

\section{Participants}

The sample consisted of 249 employees of a public hospital (78\% women), of which $46.2 \%$ are nurses, $44.6 \%$ are nursing assistants, $6 \%$ are caretakers and $3.2 \%$ are middle managers. In terms of seniority in the job, $39.4 \%$ had been in his/her unit for less than 3 years, $45.8 \%$ between 3 and 6 years, and $14.9 \%$ over 6 years. $71.2 \%$ of the participants provided their services in medical specialties, $22.4 \%$ in surgical ones, and $6 \%$ in these two areas of hospitalization.

\section{Instruments}

Psychosocial risk factors were evaluated using the FPsico Method (National Institute of Occupational Safety and Health, INSHT), composed of 75 items with Likert format (0-10 points, where 0 indicates minimal risk), and 7 factors: Mental Workload (MW), Temporal Autonomy (TA), Job Content (JC), Supervision-Participation (SP), Role Definition (RD), Worker's Interest (WI) and Personal Relationships (PR). The instrument was validated by the INSHT (Martí \& Pérez, 1997), and provides adequate evidence of reliability for the global tool, with a global Cronbach's alpha of .89, and for each dimension: .74 (MW), .87 (TA), .71 (JC), .73 (SP), .84 (RD), .84 (WI), and $.72(\mathrm{PR})$. Also validity evidence with external criteria such as health somatic symptoms (.25) and 
anxiety and fatigue (.30), and satisfaction (-.45) were provided. In our sample, Cronbach's alpha for the global score was .87 , and $.79, .85, .82, .80, .81, .87$, and .79 , were respectively the values of alpha for each dimension.

Organizational conflict was evaluated through a structured survey developed by a multidisciplinary team of experts in labor mediation in the field of Health sciences. Although there are several validated instruments for measuring organizational conflict: Thomas-Kilmann Conflict Mode (TKI) (Kilmann \& Thomas, 1977) and its further versions, or Rahim Organizational Conflict Inventory (ROCI I and II) (Rahim, 1983; Rahim \& Magner, 1995), it is important to note that this survey on conflicts was not developed as a psychometric tool. The first version of the survey including the operationalized contents was submitted to a panel of 8 experts to assess the relevance and importance of each item (searching for content validity evidence), and to elaborate a usable version. Subsequently, a pilot group of 26 professionals from all categories of Primary Care provided face validity evidence. A second pilot trial with 83 workers from several Primary Care centers was used to assess formal aspects and layout, and response time. The final version includes some sociodemographic variables (professional category, service and length of service), and consists of 4 items (multiple answers) referring to: the conflict's frequency (from Never to Always), the causes of the conflicts (workloads distribution, work organization, leadership style, workplace structure, and personal differences), the mechanisms of resolution (e.g. consulting labor unions or supervisor, changing the job, going to GP, or avoiding, denying or not facing the conflict), the consequences generated (from no consequences to rarefying of organizational climate, achievement decrease, demotivation, absenteeism, psychological problems, physical problems), and also information about whether workers would prefer to go to external mediation services to solve conflicts. This information allows the operationalization of four observable indicators of organizational conflict as a formative latent variable: Frequency, Conflict's cause/s, Conflict's resolution, and Consequences, using a Likert scale ranging from 1 to 5 points where 5 indicates the worst scenario. A more phenomenological and basic positioning underlies in the consideration to the conflict as a formative variable. On this way, the measurement of conflict summarizes four different conflicts' manifestations, mixing frequency, causes, actions, and somatic consequences.

Job satisfaction has been evaluated through four dimensions of the "Font Roja" questionnaire (Aranaz \& Mira, 1988): Task satisfaction (4 items), Professional competence (3 items), Promotion (3 items), and Status ( 2 items). The items have a Likert type response format ranging from 1 to 5 points, where 1 indicates minimal satisfaction. The instrument has obtained evidence of both internal consistency and its factorial structure, and was specifically developed for the Spanish hospital environment. Cronbach's alpha coefficients in the sample for each dimension were $.87, .84, .81$, and .79 , respectively.

\section{Procedure}

The access to the hospitalization units was facilitated by the technical area of Ergonomics and Psycho-Sociology of the Hospital Prevention Service. The plant coordinators distributed the questionnaires among their staff, and once they had been answered, participants had to put them in mailboxes enabled for this purpose. The anonymity and confidentiality of the responses was guaranteed at all times in order to minimize potential common method bias. A total of 260 questionnaires were collected from the 485 initially distributed $(51.3 \%$ response rate), of which 11 were eliminated because they presented missing values, forming a final sample of 249 participants. This study was previously approved by the Management of the Hospital Center and the Bioethics Committee of the University.

\section{Statistical analysis}

Data matrix was refined for potential errors in the data entry process. No imputation data methods were applied because participants with missing values in his/her protocol had been removed. Descriptive statistics for each observed variable in the model and multivariate normality tests to assess the underlying statistical assumptions of SEM estimation methods were performed. A Robust Maximum Likelihood method for the parameters' estimation was used despite a small degree of deviation from normality (skewness and kurtosis $z$ values below $|1.00|$ ). Covariance errors between items were not implemented for the estimated model. MPlus program (Muthén \& Muthén, 2007) was used to test the hypothesized model. The polyserial correlation matrix among all observed variables was used for the model's parameters estimation. Overall fit of the model was assessed using $\chi^{2}$, the relative/normed $\chi^{2}$ to degrees of freedom $(d f)$ ratio, the Root Mean Square Error of Approximation (RMSEA) and its $90 \%$ Confidence Interval (with the $p$-value for RMSE $A<$ 0.05), the Standardized Root Mean Squared Residual (SRMR), the Comparative Fit Index (CFI) and the Goodness of Fit Index (GFI). According to the standards, a model fit the data if $\chi^{2}$ is non-significant (but it is well-known that $\chi^{2}$ is a biased statistic by sample size so that as the power increases model fit is always inadequate), $\chi^{2} / d f<3, \operatorname{RMSE} A<.05$, $S R M R<.08$, and $C F I \geq .95$ (Hu \& Bentler, 1999). In general, a model reaches a good fit simply if the majority of these indices fulfill the cut-off values (Schreiber, Stage, King, Nora, \& Barlow, 2006). A single-common-method-factor approach for statistically controlling method biases was additionally estimated (Podsakoff, MacKenzie, Lee, \& Podsakoff, 2003). Finally, from a micro-perspective, differential analysis for searching more specific relationships among organizational conflict and the dimensional structure of the other two variables, psychosocial risk and job satisfaction was also implemented. 


\section{Results}

\section{Descriptive analysis}

Scores on psychosocial risk factors ranged from 1.36 to 6.72 points (scale from 0 "minimal risk" to 10 "maximal risk"). Personal relationships ( $M=1.36, S D=1.32)$, Role definition $(M=2.38, S D=1.56)$, Job content $(M=2.68, S D=1.31)$, Worker's interest $(M=2.72, S D=2.18)$ and SupervisionParticipation $(M=3.62, S D=2.01)$ present a tolerable risk level. The dimension Temporal autonomy $(M=4.86, S D=$ 2.66) obtained a moderate level, and Mental workload ( $M=$ $6.72, S D=1.97$ ) has the worst values of the set of psychosocial risk factors. As regards job satisfaction, with a scale ranging from 1 to 5 , the dimensions with the highest level of satisfaction are, in this order, Task Satisfaction $(M=4.00, S D=$ $0.61)$, Competence $(M=3.64, S D=0.71)$, Promotion $(M=3.14$, $S D=0.77)$ and Status $(M=2.98, S D=0.72)$. In all cases, satisfaction values are around the average value of the scale (3.00).

Finally, regarding the organizational conflict, $30.1 \%$ of participants referred that frequency conflicts was 2 or 3 times a month, 7.2\% responded that daily, and $10.4 \%$ answered that conflicts never had happened. About the causes of the last conflict, the majority attributed it to personal differences $(34.9 \%)$, to the distribution of workloads $(31.3 \%)$, and to leadership or leadership style $(14.9 \%)$. The most prevalent active resolution strategy was to contact the supervisor $(42.2 \%)$, and the passive ones were to avoid, to deny or not to confront the conflict $(14.9 \%)$. Despite the fact that the action to request help to third parties only chose a $12.9 \%$, when asked if they would request an external mediation service to solve the conflict, $75.1 \%$ answered affirmatively. Finally, regarding the consequences of having lived a conflict, almost $40 \%$ responded that there were no consequences derived from it, compared to $17.7 \%$ who expressed anxiety and irritability.
It is important to note that sociodemographic and organizational variables as sex, occupation and length of service were tested for potential different patterns regarding to psychosocial risks factor scores. Statistical tests (T-Test and One-way Anova) showed non-significant differences in psychosocial risks' scores by any of the three considered variables (in line with the results of Roland-Levy et al., 2014). Given these results, the model to be fitted only included the three main constructs: psychosocial risks, organizational conflict and job satisfaction.

The polyserial correlation matrix among all observed variables of the model was computed to fit the SEM model (Table 1). Results about the estimated model showed that a good fit to the data according to the overall good of fit indices (Figure 2). Despite the chi-square was statistically significant $\left(\chi^{2}=118.19, d f=87, p<.01\right), \chi^{2} / \mathrm{df}$ obtained a value clearly below 3 (1.36), RMSEA was equal to .04 (IC90\% = $.02 ; .05)$, and the probability of being under .05 was .88 , in addition CFI was upper than .95 (.98), and the SRMR value was lower than .08 (.05). From the analytical point of view, all estimated parameters were statistically significant at .95 confidence level. Factor loadings of the latent variable psychosocial risk ranged from .45 (Personal relationships and Worker's interest) to .52 (Mental workload) while the factor loadings of Job satisfaction ranged from .54 (Task satisfaction) to .64 (Promotion's satisfaction). The four empirical indicators of the formative latent variable Organizational conflict also were statistically significant, ranging from .52 (Frequency) to .65 (Conflict's causes). Attending to the main path coefficients among latent variables, the path from psychosocial risk to job satisfaction was $-.52(p<.01)$, and to organizational conflict was $.69(p<.01)$. Finally, the path coefficient from organizational conflict to job satisfaction was $.36(p<.01)$. According to these values, the explained variance of organizational conflict by psychosocial risk was $48 \%$, while the explained variance of job satisfaction by both psychosocial risk and organizational conflict was $66 \%$. 
Table 1. Polyserial correlation matrix among psychosocial risk factors, organizational conflict indicators and job satisfaction dimensions $(N=249)$.

\begin{tabular}{|c|c|c|c|c|c|c|c|c|c|c|c|c|c|c|c|c|}
\hline & Observed variables & 1 & 2 & 3 & 4 & 5 & 6 & 7 & 8 & 9 & 10 & 11 & 12 & 13 & 1415 & 15 \\
\hline \multirow{8}{*}{ 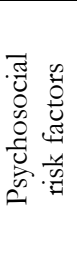 } & 1. Mental Workload & - & & & & & & & & & & & & & & \\
\hline & 2. Autonomy & $.64 * *$ & - & & & & & & & & & & & & & \\
\hline & 3. Job content & $.52 * *$ & $.54 * *$ & - & & & & & & & & & & & & \\
\hline & 4. Supervision/Participation & $.46^{* *}$ & $.47 * *$ & $.51 * *$ & - & & & & & & & & & & & \\
\hline & 5. Role definition & $.47 * *$ & $.67 * *$ & $.51 * *$ & $.50 * *$ & - & & & & & & & & & & \\
\hline & 6. Worker's interest & $.58^{* *}$ & $.55^{* *}$ & $.25^{* *}$ & $.33^{* *}$ & $.37 * *$ & - & & & & & & & & & \\
\hline & 7. Personal relationships & $.51 * *$ & $.18^{*}$ & $.56^{* *}$ & $.53^{* *}$ & $.15^{*}$ & $.42 * *$ & - & & & & & & & & \\
\hline & 8. Conflict consequences & $.43^{* *}$ & $.26^{* *}$ & $.36^{* *}$ & $.38 * *$ & $.40^{* *}$ & $.32 * *$ & $.51^{* *}$ & - & & & & & & & \\
\hline \multirow{4}{*}{ 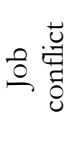 } & 9. Causes & $.32 * *$ & $.41 * *$ & $.48^{* *}$ & $.43^{* *}$ & $.41^{* *}$ & $.35^{* *}$ & $.43^{* *}$ & $.87^{* *}$ & - & & & & & & \\
\hline & 10. Conflict Actions & $.44^{* *}$ & $.41^{* *}$ & $.30 * *$ & $.37^{* *}$ & $.33^{* *}$ & $.41 * *$ & $.35^{* *}$ & $.63^{* *}$ & $.69 * *$ & - & & & & & \\
\hline & 11. Frequency & $.34 * *$ & $.53^{* *}$ & $.41 * *$ & $.31 * *$ & $.40^{* *}$ & $.42 * *$ & $.39 * *$ & $.58^{* *}$ & $.59 * *$ & $.54 * *$ & - & & & & \\
\hline & 12. Job Satisfaction & $-.49 * *$ & $-.54 * *$ & $-.52 * *$ & $-.34 * *$ & $-.48^{* *}$ & $-.45^{* *}$ & $-.37 * *$ & $-.26 * *$ & $-.44 * *$ & $-.48^{* *}$ & $-.53 * *$ & - & & & \\
\hline \multirow{3}{*}{ 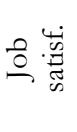 } & 13. Competence & $-.45^{* *}$ & $-.11 *$ & $-.38^{* *}$ & $-.51 * *$ & $-.32 * *$ & $-.58^{* *}$ & $-.52 * *$ & $-.39 * *$ & $-.52^{* *}$ & $-.56^{* *}$ & $-.42^{* *}$ & $.68^{* *}$ & - & & \\
\hline & 14. Promotion & $-.30 * *$ & $-.44 * *$ & $-.43 * *$ & $-.58 * *$ & $-.40 * *$ & $-.46^{* *}$ & $-.68 * *$ & $-.68 * *$ & $-.51 * *$ & $-.49 * *$ & $-.60 * *$ & $.62 * *$ & $.78^{* *}$ & - & \\
\hline & 15. Status & $-.35 * *$ & $-.37 * *$ & $-.41 * *$ & $-.42 * *$ & $-.59 * *$ & $-.45^{* *}$ & $-.38^{* *}$ & $-.25^{* *}$ & $-.71 * *$ & $-.45^{* *}$ & $-.46^{* *}$ & $.61 * *$ & $.61 * *$ & $.75^{* *}-$ & - \\
\hline
\end{tabular}

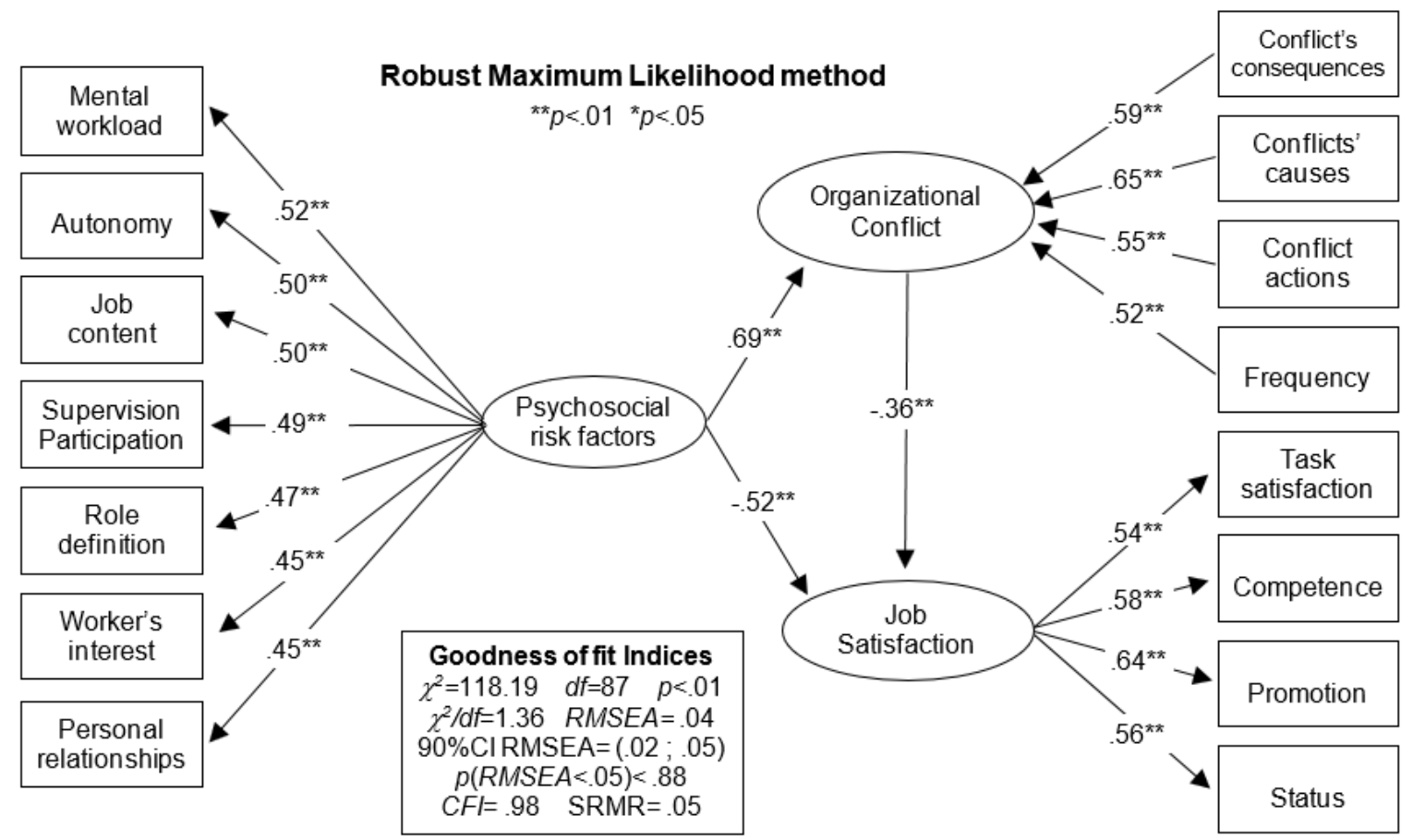

Figure 2. Estimated model with standardized path coefficients and factor loadings and Overall goodness of fit indices.

In order to statistically control the potential method bias of the measures, a single-common-method-factor approach was additionally estimated (Podsakoff et al., 2003). A common method variance latent factor was added to the initial structure with the three considered constructs. The goodness of fit indices of the model were inadequate; the chi-square was statistically significant $\left(\chi^{2}=258.84, d f=69, p<.01\right)$, $\chi^{2} /$ df obtained a value clearly greater than 3 (3.75), RMSEA was equal to $.11(\mathrm{IC} 90 \%=.09 ; .12)$, and the probability of RMSEA being under .05 was lower than .0001, in addition CFI was lower than .95 (.88), and the SRMR value was greater than .08 (.10).

Once the global theoretical model was estimated, then differential analyses regarding organizational conflict in rela- tion to psychosocial risks and job satisfaction were carried out. The frequency of the conflict as ordinal variable (low/medium/high) was statistically significant in relation to risk factors: Mental workload, Supervision-participation, Role definition and Personal relationships. In all significant cases a higher level of risk implies a higher conflict frequency. Similarly, statistical significant differences were found with the job satisfaction dimensions: task satisfaction, Competence, and Promotion (Status was non-significant). In this case the relationships are inverse to the psychosocial risk, so that the greater the frequency of the conflict, the lower the level of satisfaction (Table 2). 
Table 2. Results of ANOVA among the seven factors of psychosocial risk, the four factors of job satisfaction and the frequency of organizational conflict (low, medium, and high).

\begin{tabular}{|c|c|c|c|c|c|}
\hline \multirow[b]{3}{*}{ Psychosocial risk factors } & \multicolumn{3}{|c|}{ Frequency of Organizational Conflict } & \multirow[b]{3}{*}{$F$} & \multirow[b]{3}{*}{$p$-value } \\
\hline & Low & Medium & High & & \\
\hline & Mean (SD) & Mean (SD) & Mean (SD) & & \\
\hline Mental workload & $5.74(2.06)$ & $6.84(1.94)$ & $6.82(1.93)$ & 3.69 & .026 \\
\hline Temporal autonomy & $4.50(3.25)$ & $4.73(2.63)$ & $5.38(2.43)$ & 1.63 & .198 \\
\hline Job's content & $3.15(1.33)$ & $2.59(1.28)$ & $2.72(1.35)$ & 2.12 & .122 \\
\hline Supervision-Participation & $3.10(1.61)$ & $3.39(1.87)$ & $4.43(2.30)$ & 7.30 & .001 \\
\hline Role's definition & $1.92(1.15)$ & $2.16(1.49)$ & $3.13(1.68)$ & 10.51 & $<.0001$ \\
\hline Worker's Interest & $2.65(1.93)$ & $2.56(2.13)$ & $3.17(2.37)$ & 1.75 & .175 \\
\hline Personal relationships & $1.46(1.03)$ & $1.20(1.31)$ & $1.72(1.38)$ & 3.59 & .029 \\
\hline \multicolumn{6}{|l|}{ Job satisfaction factors } \\
\hline Task satisfaction & $4.06(0.60)$ & $4.10(0.55)$ & $3.70(0.68)$ & 10.39 & $<.0001$ \\
\hline Competence & $4.05(0.73)$ & $3.65(0.70)$ & $3.42(0.64)$ & 7.68 & .001 \\
\hline Promotion & $3.23(0.81)$ & $3.24(0.75)$ & $2.83(0.74)$ & 6.78 & .001 \\
\hline Status & $3.06(0.72)$ & $3.04(0.73)$ & $2.81(0.68)$ & 2.35 & .097 \\
\hline
\end{tabular}

Finally, it was analyzed if the most prevalent causes of organizational conflict chosen by workers (the distribution of workloads and styles of leadership or leadership) presented significant differences with regard to psychosocial risk factors and job satisfaction (Table 3). Results of t-tests showed that workers who perceived that the conflict' cause was workload distribution had higher level of mental workload $(p$ $=.04)$, lower role definition $(p=.01)$, and lower competence self-perception $(p=.02)$. In the same way, those workers who chose directive style or leadership as the cause of conflict had higher risk levels of temporal autonomy $(p=.02)$, supervision-participation $(p<.0001)$, role definition $(\phi<$ $.0001)$, and worker's interest $(p=.003)$, and lower task satisfaction $(p=.001)$ and promotion $(p=.001)$. Attending to the most prevalent mechanisms of conflict solving, those workers who did not suffer any consequences of the conflict obtained lower risk level of mental workload $(p=.003)$ and personal relationships $(\phi=.04)$; all job satisfaction factors were non-significant. The workers who referred anxiety as conflict consequence obtained higher risk levels of supervision-participation $(p=.04)$ and personal relationships $(p=$ $.007)$, and also better satisfaction levels across the four factors. By last, those workers who suffered irritability as a consequence of conflict obtained higher risk levels of supervision-participation $(p=.03)$ and role definition $(p=.04)$, and in turn, better values of satisfaction in the promotion factor $(p=.02)$.

Table 3. Results of T-Test comparisons* about by conflict's causes, mechanisms of conflict solving, and conflict consequences by psychosocial risk factors and job satisfaction.

\begin{tabular}{|c|c|c|c|c|c|}
\hline Psychosocial Risk Factors & $\begin{array}{l}\text { Levene's Test } \\
\text { significance }\end{array}$ & $\begin{array}{c}\text { T-Test } \\
\text { significance }\end{array}$ & $\begin{array}{c}\text { Job Satisfaction } \\
\text { Factors }\end{array}$ & $\begin{array}{l}\text { Levene's Test } \\
\text { significance }\end{array}$ & $\begin{array}{c}\text { T-Test } \\
\text { significance }\end{array}$ \\
\hline \multicolumn{6}{|c|}{ CONFLICT'S CAUSES } \\
\hline \multicolumn{6}{|c|}{ Workload distribution (Yes/No) } \\
\hline Mental workload & .93 & .04 & Competence & .84 & .02 \\
\hline Role definition & .10 & .01 & & & \\
\hline \multicolumn{6}{|c|}{ Directive styles -Leadership (Yes/no) } \\
\hline Temporal Autonomy & .60 & .02 & Task Satisfaction & .05 & .001 \\
\hline $\begin{array}{l}\text { Supervision- } \\
\text { Participation }\end{array}$ & .03 & $<.0001$ & Promotion & .18 & .001 \\
\hline Role definition & .10 & $<.0001$ & & & \\
\hline Worker's interest & .001 & .003 & & & \\
\hline \multicolumn{6}{|c|}{ MECHANISMS OF CONFLICT SOLVING } \\
\hline \multicolumn{6}{|c|}{ To contact supervisor (Yes/No) } \\
\hline Mental workload & .37 & .003 & Competence & .74 & .05 \\
\hline Job's content & .15 & .03 & & & \\
\hline \multicolumn{6}{|c|}{ To avoid, to deny or not to confront the conflict (Yes/No) } \\
\hline & & & Promotion & .99 & .02 \\
\hline
\end{tabular}

*Only statistically significant factors are shown in the table. 
Table 3 (cont.). Results of T-Test comparisons* about by conflict's causes, mechanisms of conflict solving, and conflict consequences by psychosocial risk factors and job satisfaction.

\begin{tabular}{|c|c|c|c|c|c|}
\hline $\begin{array}{c}\text { Levene's Test } \\
\text { significance }\end{array}$ & $\begin{array}{c}\text { T-Test } \\
\text { significance }\end{array}$ & $\begin{array}{c}\text { Job Satisfaction } \\
\text { Factors }\end{array}$ & $\begin{array}{l}\text { Levene's Test } \\
\text { significance }\end{array}$ & \multicolumn{2}{|c|}{$\begin{array}{c}\text { T-Test } \\
\text { significance }\end{array}$} \\
\hline \multicolumn{6}{|c|}{ CONFLICT CONSEQUENCES } \\
\hline \multicolumn{6}{|l|}{ No consequences (Yes/No) } \\
\hline Mental workload & .82 & .01 & & & \\
\hline Personal relationships & .0001 & .04 & & & \\
\hline \multicolumn{6}{|l|}{ Anxiety (Yes/No) } \\
\hline Supervision-Participation & .0001 & .04 & Satisfaction & .17 & .02 \\
\hline \multirow[t]{3}{*}{ Personal relationships } & .002 & .007 & Competence & .44 & .01 \\
\hline & & & Promotion & .66 & .04 \\
\hline & & & Status & .84 & .04 \\
\hline \multicolumn{6}{|l|}{ Irritability (Yes/No) } \\
\hline Supervision-Participation & .38 & .03 & Promotion & .87 & .02 \\
\hline Role definition & .43 & .04 & & & \\
\hline
\end{tabular}

* Only statistically significant factors are shown in the table.

\section{Discussion}

The aim of this study was to evaluate the potential effects of psychosocial risk factors on organizational conflict and job satisfaction in a sample of Health professionals by means of a SEM approach.

Both the overall fit of the model (RMSE $A=.04)$ and the analytic fit of each parameter $(p<.05)$ were adequate. A single-common-method-factor was implemented in order to assess the potential method biases of the measures. A clearly inadequate fit (RMSE $A=.11)$ for the common method model showed the non-significant influence of biases. So, the findings of the main model have shown that job satisfaction and its dimensions present a negative relational pattern $(r=$ $\left..52 ; r^{2}=.27\right)$ regarding psychosocial risk factors, in line with Acker (2004), Aust and Ducki (2004), Cortese et al. (2010), Kompier et al. (2000), and Kristensen (2000). Evidence also shows that the causes of conflict, their frequency, resolution mechanisms and their consequences are negatively influenced by psychosocial risk factors $\left(r=.69 ; r^{2}=.48\right)$, and in turn, conflict has a negative effect on satisfaction $(r=-.36 ; r$ ${ }^{2}=.13$ ). An indirect statistically significant effect from psychosocial risks to job satisfaction through the organizational conflict is also obtained $\left(r=-.25 ; r^{2}=.06\right)$. This empirical evidence is in line with that provided by Kaitelidou et al. (2012) and Kim et al. (2017), which emphasize organizational problems as the main factor generating conflicts, especially receiving different guidelines from different supervisors and communication gaps; that is, paradigmatic factors of psychosocial risk. Differential analysis brings light for showing that an inappropriate leadership style as a cause of conflict is related to all psychosocial factors that have a direct or indirect relationship with leadership aspects such as temporal autonomy, supervision-participation, role definition and worker's interest. In terms of satisfaction, it influences in particular the dimensions of job satisfaction and promotion. These findings are consistent with those obtained by Almost et al. (2010), which show that the relationship with supervisors and peers influences the level of perception of conflicts, and this in turn in job satisfaction. Again, both supervision and leadership appear as the key aspects of conflict management. As for the frequency of the conflict, statistically significant effects regarding the majority of psychosocial risk factors and job satisfaction are obtained. Therefore, evidence about that a lower frequency of conflict contributes to the improvement of the perception of the psychosocial environment and the satisfaction of the staff is strongly related to the findings of Hyde et al. (2006), Benitez et al. (2012) or Chen et al. (2012).

With respect to conflict resolution mechanisms, this study shows that "going to the supervisor" has been chosen as the most prevalent strategy to solve conflicts $(42.2 \%)$. However, $75.1 \%$ of the participants would request a mediation process from an impartial professional. These data can be interpreted so that, even if the supervisor is approached to solve the conflict, it is perceived that this way will not be completely satisfactory. Thus, in line with McDonald et al. (2010) and Chen et al. (2012), evaluating and training managers in conflict resolution must be assumed as a core competency of the professional skills of all supervisors.

Finally, the model posited that the consequences of conflict may be conditioned by the perception of psychosocial risks and negatively influence satisfaction. Both the professionals to whom the conflict has generated anxiety or irritability, as well as those who have not had effects, show differences in the aspects most related to leadership and personal relationships. This empirical evidence can be interpreted in the sense that those participants who have not suffered the consequences of having conflicts are more comfortable and more satisfied with the supervision exercised and with the partners, than those who have suffered anxiety or irritability.

In conclusion, the empirical evidence provided confirms the potentiating effect that psychosocial risks exert on organizational conflict and the negative effect on job satisfaction; and also how organizational conflict plays a role of negative mediator between psychosocial risks and satisfaction. As one of the unique contribution of this study, and at our knowledge, it is the first time that a complex model of rela- 
tionships between the three constructs is tested with a SEM approach. These findings, limited to Health organizational context as one of the most psychosocially risk impacted sector, are really important to make more visible for $\mathrm{H} \& \mathrm{~S}$ stakeholders the negative effects over organizational conflicts and job satisfaction, and to encourage them for considering psychosocial risk prevention as a priority strategy (Langehan et al., 2013).

The obtained evidence highlights the importance of those psychosocial risks factors more related to leadership and supervision, and contributes to put in value the need for designing and implementing intervention programs for reducing psychosocial risks and organizational conflict, and in turn, increasing job satisfaction of Health professionals.

\section{References}

Acker, G. M. (2004). The effect of organizational conditions (role conflict, role ambiguity, opportunities for professional development, and social support) on job satisfaction and intention to leave among social workers in mental health care. Community Mental Health Journal, 40(1), 65-73.

Almost, J., Doran, D.M., Hall, L., \& Laschinger, H. K. (2010). Antecedents and consequences of intra-group conflict among nurses. Journal of Nursing Management, 18(8), 981-992.

Aranaz, J. \& Mira, J. (1988). Cuestionario Font Roja. Un instrumento de medida de satisfacción en el medio hospitalario. Todo Hospital, 52, 6366.

Aust, B., \& Ducki, A. (2004). Comprehensive health promotion interventions at the workplace: experiences with health circles in Germany. Journal of Occupational Health Psychology, 9 (3), 258.

Baeriswyl, S., Krause, A., \& Schwaninger, A. (2016). Emotional exhaustion and job satisfaction in airport security officers-Work-family conflict as mediator in the job demands-resources model. Frontiers in Psychology, 7, 663 .

Benítez, M., Medina, F. J., \& Munduate, L. (2012). La gestión de conflictos relacionales en las organizaciones de servicios. Anales de Psicología, 28(1), $139-149$.

Bültmann, U., Kant, I. J., Van den Brandt, P. A., \& Kasl, S. V. (2002). Psychosocial work characteristics as risk factors for the onset of fatigue and psychological distress: Prospective results from the Maastricht Cohort Study. Psychological Medicine, 32(2), 333-345.

Chen, X. H., Zhao, K., Liu, X. \& Wu, D. D. (2012). Improving employees' job satisfaction and innovation performance using conflict management. International Journal of Conflict Management, 23(2), 151-172.

Choi, Y. (2013). The influence of conflict management culture on job satisfaction. Social Behavior and Personality, 41(4), 687-692.

Coelho, D. A., Tavares, C. S., Lourenço, M. L., \& Lima, T. M. (2015). Working conditions under multiple exposures: A cross-sectional study of private sector administrative workers. Work, 51(4), 781-789.

Cortese, C. G., Colombo, L., \& Ghislieri, C. (2010). Determinants of nurses' job satisfaction: The role of work-family conflict, job demand, emotional charge and social support. Journal of Nursing Management, 18(1), 35-43.

European Agency for Health and Safety at Work (EU-OSHA) (2007). Expert forecast on emerging psychosocial risks related to occupational health and safety. Luxembourg: Office for Official Publications of the European Communities.

Freimann, T., \& Merisalu E. (2015). Work-related psychosocial risk factors and mental health problems amongst nurses at a university hospital in Estonia: A cross-sectional study. Scandinavian Journal of Public Health, 43(5), 447-452.

Guerra, J. M., Martínez, I., Munduate, L., \& Medina, F. J. (2005). A contingency perspective on the study of the consequences of conflict types: The role of organizational culture. European Journal of Work and Organizational Psychology, 14(2), 157-176.

\section{Limitations and future research}

However, the cross-sectional nature of this study does not allow testing the potential existence of circular patterns, which have to be the reason for future works by longitudinal designs. Also common method variance biases have been partially controlled. Future research must be oriented to analyze the invariance of the fitted model across other professional settings (not only Health). Also a longitudinal approach can be useful to analyze processes and non-recursive SEM models.

Hall, G. B., Dollard, M. F., Coward, J. (2010). Psychosocial safety climate: Development of the PSC-12. International Journal of Stress Management, 17(4), 353-383.

Hu, L., \& Bentler, P. M. (1999). Cutoff criteria for fit indexes in covariance structure analysis: conventional criteria versus new alternatives. Struc tural Equation Modeling, 6, 1-55.

Hyde, M., Jappinen, P., Theorell, T., \& Oxenstierna, G. (2006). Workplace conflict resolution and the health of employees in the Swedish and Finnish units of an industrial company. Social Science \& Medicine, 63(8), 2218-2227.

Kaitelidou, D., Kontogianni, A., Galanis, P., Siskou, O., Mallidou, A., Pavlakis, A., et al. (2012). Conflict management and job satisfaction in paediatric hospitals in Greece. Journal of Nursing Management, 20(4), 571 578 .

Kilmann, R. H., \& Thomas, K. W. (1977). Developing a forced-choice measure of conflict-handling behavior: the MODE instrument. Educational and Psychological Measurement, 37(2), 309-325.

Kim, S., Bochatay, N., Relyea-Chew, A., Buttrick, E., Amdahl, C., Kim, L., Frans, E., Mossanen, M., Khandekar, A., Fehr, R., \& Lee, Y.M. (2017). Individual, interpersonal, and organisational factors of healthcare conflict: A scoping review. Journal of Interprofessional Care, 31(3), 282-290.

Kompier, M. A., Aust, B., van den Berg, M., \& Siegrist, J. (2000). Stress prevention in bus drivers: evaluation of 13 natural experiments. Journal of Occupational Health Psychology, 5 (1), 11.

Kristensen, T. S. (2000). Workplace intervention studies. Occupational Medicine, 15 (1), 293.

Langenhan, M., Leka, S., \& Jain, A. (2013). Psychosocial risks: is risk management strategic enough in business and policy making? Safety and Health at Work, 4(2), 87-94.

Lee, H. E. (2009). Communication network approaches to conflict management at the workplace and job satisfaction. Dissertation Abstracts In ternational Section A: Humanities and Social Sciences, 69(9-A), 3743.

Leka, S., Van Wassenhove, W., \& Jain, A. (2015). Is psychosocial risk prevention possible? Deconstructing common presumptions. Safety Science, 71, 61-67.

Lin, S. M. (2003). Relationship among conflict management styles, employees' job satisfaction and team effectiveness: A comparison between public and private hospitals in Taiwan (China). Dissertation Abstracts International Section A: Humanities and Social Sciences, 64(5-A), 1750.

López-Montesinos, M. J. (2013). Psychosocial study about the consequences of work in hospital nurses as human resource management. Revista Latino-Americana de Enfermagem, 21, 61-70.

Marti, F. \& Pérez, J. (1997). NTP 443: Factores psicosociales: metodología de evaluación. Ministerio de Trabajo y Asuntos Sociales: INSHT.

Martín, J., Luceño, L., Jaén, M., \& Rubio, S. (2007). Relation between adverse psychosocial risks, assessed by means of the DECORE Multidimensional Questionnaire, and deficient occupational health. Psicothema, 19(1), 95-101. 
McCaughey, D., Turner, N., Kim, J., Dellifraine, J., \& McGhan, J. E. (2015). Examining workplace hazard perceptions and employee outcomes in the long-term care industry. Safety Science, 78, 190-197.

McDonald, G., Vickers, M. H., Mohan, S., Wilkes, L., \& Jackson, D. (2010). Workplace conversations: Building and maintaining collaborative capital. Contemporary Nurse, 36(1-2), 96-105.

Montoro-Rodriguez, J. \& Small, J. A. (2006). The Role of Conflict Resolution Styles on Nursing Staff Morale, Burnout, and Job Satisfaction in Long-Term Care. Journal of Aging Health, 18(3), 385-406.

Muthén, L. K., \& Muthén, B. O. (2007). Mplus User's Guide (Sixth Edition). Los Angeles, CA: Muthén \& Muthén.

Olivares-Faúndez, V. E., Gil-Monte, P. R., Mena, L., Jélvez-Wilke, C., \& Figueiredo-Ferraz, H. (2014). Relationships between burnout and role ambiguity, role conflict and employee absenteeism among health workers. Terapia Psicológica, 32(2), 111-120.

Piko, B. F. (2006). Burnout, role conflict, job satisfaction and psychosocial health among Hungarian health care staff: A questionnaire survey. International Journal of Nursing Studies, 43(3), 311-318.

Podsakoff, P. M., MacKenzie, S. B., Lee, J. Y., \& Podsakoff, N. P. (2003). Common method biases in Behavioral research: A critical review of the literature and recommended remedies. Journal of Applied Psychology, 88 (5), 879-903.

Rahim, M. A. (1983). A measure of styles of handling interpersonal conflict. Academy of Management Journal, 26, 368-376.

Rahim, M. A., \& Magner, N. (1995). Confirmatory factor analysis of the styles of handling interpersonal conflict: first-order factor model and its invariance across groups. Journal of Applied Psychology, 80(1), 122-132.

Roland-Lévy, C., Lemoine, J., \& Jeoffrion, C. (2014). Health and well-being at work: The hospital context. Revue européenne de psychologie appliquée, 64, 53-62.

Saastamoinen, P., Laaksonen, M., Leino-Arjas, P., \& Lahelma, E. (2009). Psychosocial risk factors of pain among employees. European Journal of Pain, 13(1), 102-108.

Scher, K. M. (2006). Conflict management style of nurse managers and its impact upon staff nurse job satisfaction. Dissertation Abstracts International Section A: Humanities and Social Sciences, 67(2-A), 740.
Schreiber, J. B., Stage, F. K., King, J., Nora, A., \& Barlow, E. A. (2006). Reporting structural equation modeling and confirmatory factor analysis results: A review. The Journal of Educational Research, 99, 323-337.

Soler, M. I., Fernández, M. M., \& de Pedro, M. (2016). The moderating role of resilience in situations of work role demands and self-perceived discomfort. Revista Mexicana de Psicología, 33(1), 61-70.

Springs, M. J. (2016). Examining organizational conflict management style climate: Moderator of job satisfaction and intent to leave a management consulting organization. Dissertation Abstracts International Section A: Humanities and Social Sciences, 77(3-A)(E).

Tabak, N. \& Koprak, O. (2007). Relationship between how nurses resolve their conflicts with doctors, their stress and job satisfaction. Journal of Nursing Management, 15(3), 321-331.

Todorova, G., Bear, J. B., \& Weingart, L. R. (2014). Can conflict be energizing? A study of task conflict, positive emotions, and job satisfaction. Journal of Applied Psychology, 99(3), 451-467.

Tomaschek, A., Lütke, S. S., Melzer, M., Debitz, U., \& Buruck, G. (2018). Measuring work-related psychosocial and physical risk factors using workplace observations: a validation study of the "Healthy Workplace Screening". Safety Science, 101, 197-208.

Torressen, A. M. (2000). A study to examine perceived role ambiguity, role conflict, participation in decision making, ability and job satisfaction among intellectual property licensing professionals. Dissertation Abstracts International Section A: Humanities and Social Sciences, 61(4-A), 1269.

Toukas, D., Delichas, M., Toufekoula, C., \& Spyrouli, A. (2015). The Role of Labour Inspectorates in Tackling the Psychosocial Risks at Work in Europe: Problems and Perspectives. Safety and Health at work, 6, 263267.

Walters, D. (2011). Worker representation and psycho-social risks: A problematic relationship? Safety Science, 49, 599-606.

Williams, I. A. (2012). Conflict management styles and job satisfaction by organizational level and status in a private university. Dissertation $A b$ stracts International Section A: Humanities and Social Sciences, 73(4-A), 1487.

Yang, Y. F. (2014). Transformational leadership in the consumer service workgroup: Competing models of job satisfaction, change commitment, and cooperative conflict resolution. Psychological Reports, 114(1), $33-49$. 